\title{
Cochlear Gene Therapy
}

\author{
Lawrence R. Lustig, MD and Omar Akil, PhD
}

Francis A. Sooy, MD Professor of Otolaryngology-Head \& Neck Surgery, Department of Otolaryngology-Head \& Neck Surgery, University of California San Francisco, 2380 Sutter Street, San Francisco, CA 94115, PH: 415-353-2203, llustig@ohns.ucsf.edu

\section{Abstract}

The purpose of this review is to highlight recent advances in cochlear gene therapy over the past several years. Cochlear gene therapy has undergone tremendous advances over the past decade. Beginning with some groundbreaking work in 2005 documenting hair cell regeneration using virallymediated delivery of the mouse atonal 1 gene, gene therapy is now being explored as a possible treatment for a variety of causes of hearing loss.

Recent advances in cochlear gene therapy include improved methods of gene delivery with a better delineation of viral vectors that are suitable for this purpose, additional improvements in hair cell regeneration, and directed research towards autoimmune hearing loss, ototoxicity, spiral ganglion survival, and genetic forms of hearing loss.

If successful, cochlear gene therapy will dramatically alter our ability to treat a variety of forms of acquired and genetic hearing loss.

\section{Introduction}

Hearing loss is one of the most common human sensory deficits, affecting over 200 million people worldwide. Acquired forms of hearing loss represent a majority of these cases, including such pathologies as presbycusis, noise-exposure, infection and ototoxicity. Congenital forms of hearing loss occur in approximately 1.5 in 1000 children.(1) Of these, about $1 / 2$ are attributed to a genetic basis.(2) These genetic forms of hearing loss have been classified based upon associated systemic findings (syndromic forms of hearing loss), and in those with isolated cochlear findings, the mode of inheritance (autosomal dominant-DFNA; autosomal recessive DFNB; $x$-chromosome linked DFNX; and y-chromosome linked DFNY). Autosomal recessive inheritance dominates non-syndromic modes of hereditary deafness, comprising approximately $80 \%$ of all prelingual onset forms.(3) To date, elucidation of the mechanisms of genetic hearing loss has led to some fundamental advances in our understanding of auditory transduction and the critical molecular pathways involved in normal hearing.(4)

While our understanding of the causes of both genetic and acquired forms of sensorineural hearing loss has advanced tremendously over the past 20 years, treatments have advanced little over that same time period, and generally consist of hearing amplification for mild to severe losses, and cochlear implantation for severe to profound losses. There is no question that cochlear implantation has profoundly influenced our treatment of patients with deafness, but there are still significant limitations in function with an implant, and results

This is a PDF file of an unedited manuscript that has been accepted for publication. As a service to our customers we are providing this early version of the manuscript. The manuscript will undergo copyediting, typesetting, and review of the resulting proof before it is published in its final citable form. Please note that during the production process errors may be discovered which could affect the content, and all legal disclaimers that apply to the journal pertain. 
cannot compare to normal hearing.(5) There thus remains intense interest in restoring normal organ of Corti function through such techniques as gene therapy.(2)

Gene therapy for inner ear disorders has developed along two major lines: hair cell or sensory regeneration and gene therapy for genetic deafness. To date, a majority of the research in this arena has focused on either the methodology of effective cochlear gene transfer or specific applications such as hair cell regeneration.

\section{Methods for Cochlear Delivery}

In order for gene therapy to be effective, the required gene must be appropriately delivered both temporally and spatially. Two methods can be used to drive protein expression in specific cell types: cell-specific promoters and specific viral subtypes. To date, a number of vectors have been tried for cochlear gene delivery. Non-viral vectors, including plasmids alone or packaged within lipids, have the theoretic advantage of reduced toxicity and inflammation associated with virally-mediated gene transfer. Unfortunately, these methods demonstrate low transduction efficiency and poor trans-gene expression patterns, limiting their usefulness. $(6,7)$ One recent novel approach used nanoparticles to successfully deliver hyperbranched polylysine particles into the rat cochlea.(8) Whether such an approach could be applied to gene delivery remains to be seen, however.

More recent efforts have focused on the use of specific viral subtypes to drive expression in particular cells. To date, adenovirus, adeno-associated virus, herpes simplex virus, vaccinia virus, retrovirus, helper-dependent adenovirus and lentivirus have all tested for cochlear gene delivery.(6) Of these, the one that has demonstrated the most potential is adenoassociated virus (AAV): it is nonreplicating, can efficiently transfer transgenes to the inner ear, and causes no ototoxicity.(6, 9-12) In particular, AAV can effectively transfect inner hair cells, a critical feature if one hopes to correct genetic defects due to hair cell-specific mutations. To date, a number of different AAV subtypes have been used with success for cochlear gene delivery, demonstrating little if any damage to the organ of Corti.(10) (13) A recent report studying AAV serotypes 1, 2, 5, 6 and 8 demonstrated successful gene expression in hair cells, supporting cells, the auditory nerve and spiral ligament, with hair cells being the most effectively transduced.(13) One of the greatest limitations of AAV is the maximum gene insert size of $\sim 5 \mathrm{~kb}$, significantly limiting the number of genes that can be transduced.(14)

In contrast to AAV, adenovirus has several advantages for cochlear gene therapy, including larger potential insert size, greatly expanding the number of target genes, and the wide number of cochlear cell types that have been effectively transfected, including stria vascularis, spiral ligament, hair cells and organ of Corti supporting cells.(14) Lentivirus has also been recently suggested as an agent for cochlear gene therapy. One report has demonstrated that lentivirus injected into the rat scala tympani is limited to the cochlea without evidence of spread to the central nervous system, an important feature to minimize toxicity to tissues outside the cochlea.(15).

Advances have also been made with the technique of viral delivery. While a majority of studies describe viral delivery via a cochleostomy or through direct round-window injection, one study has shown that partial enzymatic digestion of the round window membrane with a collagenase solution greatly increases permeability of AAV delivery to the cochlea without causing hearing loss and was healed within 4 weeks.(16)

\section{Hair cell regeneration using Atonal}

To date, hair cell regeneration has seen the greatest focus and successes in cochlear gene therapy, largely because it would be applicable to the most common forms of hearing loss, 
including presbycusis, noise-induced hearing loss, and hearing loss due to infection, trauma and ototoxicity. The most promising work involves studies on the atonal gene product Atoh1 (Math1 in the mouse), that encodes a transcription factor inducing the development of sensory hair cells from supporting cells in the cochlea.(17) Following the initial success reported by Izumikawa and colleagues(18) several studies have now demonstrated regeneration of hair cells with the virally-mediated delivery of Math1 in mice.(19-21) In addition to hair cell regrowth, Izumikawa et al also reported substantial improvement of hearing thresholds in deaf mice, thus demonstrating both cellular and functional rescue of hearing loss.(18) Studies in a mouse model of aminoglycoside vestibulotoxicity have also demonstrated hair cell regeneration and functional vestibular recovery following virallymediated delivery of Math1.(6, 22, 23) Similar results have also been seen in the rat cochlea. (24)

\section{Gene Therapy for Ototoxicity}

While Atoh1 gene therapy could be useful for the late effects of aminoglycocide ototoxicity and hair cell death, some investigators are also exploring the possibility of ameliorating the ototoxicity of aminoglycocide at the outset of therapy. A recent study by Zheng et al(25) has shown that AAV2-mediated expression of activity-dependent neurotrophic factor-9 (ADNF-9) in transfected rat neonatal organ of Corti explants prevented hair cell loss induced by the addition of aminoglycocide antibiotics. Further, the authors documented that transfected ADNF-9 in dorsal root ganglia cultures from chicken ADNF-9 protein could promote neuronal survival and neurite outgrowth.

\section{Neuronal Preservation}

Preservation of spiral ganglion neurons has also been the focus of multiple cochlear gene therapy studies. One study by Wise et al, aiming to prevent spiral ganglion neuronal degeneration as a result of aminoglycocide ototoxicity, used AAV-mediated transfection of the neurotrophins brain derived neurotrophic factor (BDNF) and neurotrophin-3 (NT3), in animals deafened for up to 8 weeks prior to viral delivery.(26) Importantly, the authors demonstrated that viral transfection of cells was possible even after severe degeneration of the organ of Corti, including supporting cells (pillar and Deiters' cells), stria vascularis, spiral ligament, endosteal cells lining the scala compartments and interdental cells in the spiral limbus. Further, the authors documented a significant increase in spiral ganglion survival in the entire basal turn for cochleae that received gene therapy compared to controls, with decreasing spiral ganglion survival with a longer time between deafness and viral delivery, suggesting a 'window of opportunity' in which gene therapy can provide spiral ganglion support. Another study using AAV-mediated delivery of BDNF by Shibata et al.(12) demonstrated that forced expression of BDNF in epithelial or mesothelial cells in deafened guinea pigs induced regrowth of nerve fibers towards the cells that secrete the neurotrophin. Further, the authors demonstrated that this neuronal regeneration was accompanied by a preservation of the spiral ganglion neurons. One additional recent study, using a blast-exposure model of hearing loss in rats, used adenovirus-mediated human $\beta$ nerve growth factor (Ad-hNGF $\beta$ ) gene transfer.(27) The group showed that the ABR threshold shifts in the NGF $\beta$-transfected group were significantly smaller than that of nontransfected controls. Of note, transgene expression did not last beyond 8 weeks in these animals. Lastly the group showed that the number of spiral ganglions in the transfected group was significantly greater than that of the non-transfected controls.

\section{Autoimmune hearing loss}

Autoimmune hearing loss has also been the focus of some recent cochlear gene therapy studies. In one experimental model of autoimmune hearing loss in an interleukin-10 (IL-10) 
deficient mouse, the authors demonstrated that lack of IL-10 led to a more robust autoimmune response in the ear, while IL-10 directly delivered to the cochlea led to hearing improvement.(28)

\section{Genetic Hearing Loss}

While the efforts to regenerate or preserve auditory or vestibular sensory neuroepithelium in normal animals using such techniques as Math1 hair cell regeneration are quite important, they still do not address the problem of an underlying causative genetic mutation. In such a scenario, even successfully regenerated hair cells will still be subject to the innate genetic mutation that led to hair cell loss in the first place. Thus, for genetic disorders leading to congenital or early-onset hearing loss, the optimal solution is defective gene replacement. However, rescuing genetic deafness poses much greater challenges than these other forms of cochlear gene therapy. For example, in contrast to hair cell regeneration, where one needs only short-term expression of the appropriate gene(s), for genetic deafness, lifelong expression will be required. This likely accounts for the scant number of publications on gene therapy for genetic deafness.

To date, efforts to restore hearing in genetic types of hearing loss with gene therapy have met with limited, if any success. In one of the few studies to document some successful results, Maeda et al, attempted to restore the hearing loss in a model of Connexin 26-induced deafness using AAV-transduced antisense oligonucleotides for RNA interference (RNAi). (29) In this model, the hearing loss was induced first by introducing the defective gene in a normal animal, and then using RNAi to suppress the defective gene and reverse the hearing loss. According to Maeda et al, types of deafness in which these 'gain-of-function' mutations which would potentially be amenable to such RNAi techniques include DFNA2 (KCNQ4), DFNA3 (GJB2) and DFNA5 (DFNA5).(29) Another study reported that connexin-26 expressed in a bacterial artificial chromosome in a connexin-30 knockout mouse was able to restore hearing in this model. Since connexin-related deafness accounts for a majority of cases of genetic deafness, these results represent promising, though preliminary breakthroughs in this arena.

Beyond connexins, one study by Kesser et al evaluated the potassium channel KCNQ4, defective in the deafness seen in DFNA2, an isolated autosomal dominant form of deafness. (30) The authors demonstrated that adenoviral-mediated delivery of KCNQ4 can transfect cultured human vestibular tissue. To date no functional recovery data has been documented in animal models however.

\section{Conclusions}

The cochlea remains an ideal target for gene delivery, given its confined compartments in which the agent can be delivered, with minimal risk to surrounding tissues. To date the most important advances have occurred using virally-mediated delivery of the atonal gene to induce hair cell regeneration, and offers the most immediate promise of clinical application in selected forms of deafness and loss of vestibular function. As gene delivery methods improve, we can expect to see important advances in the treatment of a variety of causes of hearing loss over the coming decade.

\section{Acknowledgments}

We would like to acknowledge the support of Hearing Research, Inc (HRI) and the American Otologic Society. 


\section{Bibliography}

1. Smith RJ, Bale JF Jr. White KR. Sensorineural hearing loss in children. Lancet. Mar 5-11.2005 365:879. [PubMed: 15752533]

2. Di Domenico M, et al. Towards gene therapy for deafness. J Cell Physiol. Dec 29.2010

3. Petersen MB, Willems PJ. Non-syndromic, autosomal-recessive deafness. Clin Genet. May.2006 69:371. [PubMed: 16650073]

4. Dror AA, Avraham KB. Hearing impairment: a panoply of genes and functions. Neuron. Oct 21.2010 68:293. [PubMed: 20955936]

5. Kral A, O'Donoghue GM. Profound deafness in childhood. The New England journal of medicine. Oct 7.2010 363:1438. [PubMed: 20925546]

6. Husseman J, Raphael Y. Gene therapy in the inner ear using adenovirus vectors. Adv Otorhinolaryngol. 2009; 66:37. [PubMed: 19494571]

7. Staecker H, Li D, O’Malley B, Van De Water TR. Gene expression in the mammalian cochlea: a study of multiple vector systems. Acta Otolaryngol. 2001; 121:157. [PubMed: 11349769]

*8. Zhang W, et al. Nuclear entry of hyperbranched polylysine nanoparticles into cochlear cells. International Journal of Nanomedicine. 2011; 6:535. [PubMed: 21468356] This manuscripts represents one of the first efforts to use nanotherapy for the delivery of genetic material into the cochlea. The study demonstrated that hyperbranched polylysine nanoparticles could be delivered to cultured cochlear cells in a concentration-dependent manner.

9. Ballana E, et al. Efficient and specific transduction of cochlear supporting cells by adeno-associated virus serotype 5. Neurosci Lett. Sep 12.2008 442:134. [PubMed: 18601973]

10. Konishi M, Kawamoto K, Izumikawa M, Kuriyama H, Yamashita T. Gene transfer into guinea pig cochlea using adeno-associated virus vectors. J Gene Med. Jun.2008 10:610. [PubMed: 18338819]

11. Praetorius M, et al. Adenoviral vectors for improved gene delivery to the inner ear. Hear Res. Feb. 2009 248:31. [PubMed: 19105978]

12. Shibata SB, Di Pasquale G, Cortez SR, Chiorini JA, Raphael Y. Gene transfer using bovine adenoassociated virus in the guinea pig cochlea. Gene Ther. Aug.2009 16:990. [PubMed: 19458651]

$* * 13$. Kilpatrick LA, et al. Adeno-associated virus-mediated gene delivery into the scala media of the normal and deafened adult mouse ear. Gene Ther. Jan 6.2011 This is an excellent study demonstrating how adeno-associated viruses can tansfect a number of types of cells within the organ of Corti in adult mice. A number of AAV serotypes are explored and the transfection characteristics are described for each cell type within the organ of Corti.

14. Kesser BW, Lalwani AK. Gene therapy and stem cell transplantation: strategies for hearing restoration. Adv Otorhinolaryngol. 2009; 66:64. [PubMed: 19494573]

*15. Duan M, Mi Q. Local delivery of reporter gene to the cochlea does not spread to brain tissue in an animal model. Acta Otolaryngol. 2010; 130:25. [PubMed: 19452334] This study documents that viral delivery of genetic material to the cochlea does not spread to the brain, addressing one of the major concerns of cochlear gene therapy. The results of this study provide further support for the safety of inner ear virall-mediated gene delivery.

*16. Wang H, et al. Efficient cochlear gene transfection in guinea-pigs with adenoassociated viral vectors by partial digestion of round window membrane. Gene Ther. 2011; 1 This study documents improved viral delivery into the cochlea by partially digesting the round window membrane, without effecting hearing in this animal model. The result offers a potential method of improved gene delivery into the inner ear.

17. Cotanche DA, Kaiser CL. Hair cell fate decisions in cochlear development and regeneration. Hear Res. Jul.2010 266:18. [PubMed: 20438823]

18. Izumikawa M, et al. Auditory hair cell replacement and hearing improvement by Atoh1 gene therapy in deaf mammals. Nat Med. Mar.2005 11:271. [PubMed: 15711559]

19. Izumikawa M, Batts SA, Miyazawa T, Swiderski DL, Raphael Y. Response of the flat cochlear epithelium to forced expression of Atoh1. Hear Res. Jun.2008 240:52. [PubMed: 18430530]

20. Kawamoto K, Ishimoto S, Minoda R, Brough DE, Raphael Y. Math1 gene transfer generates new cochlear hair cells in mature guinea pigs in vivo. J Neurosci. Jun 1.2003 23:4395. [PubMed: $12805278]$ 
21. Praetorius M, et al. Adenovector-mediated hair cell regeneration is affected by promoter type. Acta Otolaryngol. May 27.2009 :1. [PubMed: 19707904]

22. Baker K, Brough DE, Staecker H. Repair of the vestibular system via adenovector delivery of Atoh1: a potential treatment for balance disorders. Adv Otorhinolaryngol. 2009; 66:52. [PubMed: 19494572]

23. Staecker H, Praetorius M, Baker K, Brough DE. Vestibular hair cell regeneration and restoration of balance function induced by math1 gene transfer. Otol Neurotol. Feb.2007 28:223. [PubMed: 17255891]

24. Huang Y, et al. New ectopic vestibular hair cell-like cells induced by Math1 gene gransfer in postnatal rats. Brain Res. 2009; 1276:31. [PubMed: 19397899]

25. Zheng G, Zhu K, Wei J, Jin Z, Duan M. Adeno-associated viral vectormediated expression of NT4-ADNF-9 fusion gene protects against aminoglycoside-induced auditory hair cell loss in vitro. Acta Otolaryngol. 2011; 131:136. [PubMed: 21062116]

26. Wise AK, et al. The effect of deafness duration on neurotrophin gene therapy for spiral ganglion neuron protection. Hear Res. 2010; 278:69. [PubMed: 21557994]

27. Wu J, Liu B, Fan J, Zhu Q, Wu J. Study of protective effect on rat cochlear spiral ganglion after blast exposure by adenovirus-mediated human $\beta$-nerve growth factor gene. Am J Otolaryngol Head Neck Med Surg. 2011; 32:8.

28. Zhou B, et al. Experimental autoimmune hearing loss is exacerbated in IL-10-deficient mice and reversed by IL-10 gene transfer. Gene Ther. 2011:1.

29. Maeda Y, Sheffield AM, Smith RJ. Therapeutic regulation of gene expression in the inner ear using RNA interference. Adv Otorhinolaryngol. 2009; 66:13. [PubMed: 19494570]

30. Kesser B, Hashisaki G, Fletcher K, Eppard H, Holt J. An in vitro model system to study gene therapy in the human ear. Gene Ther. 2007; 14:1121. [PubMed: 17568767] 
- A number of advances have been made using cochlear gene therapy to treat various forms of hearing loss, including ototoxicity, and genetic and autoimmune hearing loss.

- Virally-mediated delivery of the atonal1 (Atoh1) gene has resulted in auditory and vestibular hair cell regeneration with limited restoration of function in mouse models of cochlear and vestibular toxicity

- At present, adenovirus and adeno-associated virus delivery appear to be the most effective means of gene delivery to the inner ear

- Future successes of cochlear gene therapy will rely upon improved targeted gene delivery and appropriate timing and length of transgene delivery 